\title{
Process Integration and Opportunities for Heat Pumps in industrial Processes*
}

\author{
H. Becker ${ }^{1 * *}$, F. Maréchal ${ }^{2}$, A. Vuillermoz ${ }^{3}$ \\ ${ }^{1,2}$ Industrial Energy Systems Laboratory (LENI), Ecole Polytechnique Fédérale de Lausanne \\ CH-1015 Lausanne, Switzerland \\ ${ }^{3}$ EDF R\&D, Eco-efficiency and Industrial Process Department, Centre des Renardières \\ F-77818 Moret-sur-Loing Cedex, France \\ E-mail: ${ }^{1}$ helen.becker@epfl.ch; ${ }^{2}$ francois.marechal@epfl.ch; ${ }^{3}$ aurelie.vuillermoz@edf.fr
}

\begin{abstract}
Process integration methods allow one optimizing industrial processes. The main goals are decreasing energy demand and operating costs as well as reducing pollutants emissions. High fuel costs promote installations of heat pumps. In a heat pump, process waste heat is valorized by electrical power to produce higher quality heat. This energy is used to satisfy a part of the process demand so that less fuel is required and $\mathrm{CO}_{2}$ emission will decrease. Based on pinch analysis, this paper presents a methodology to identify heat pump opportunities in industrial processes. The method considers the whole process including utilities and the energy conversion system. A combined analysis which considers thermal and material streams in the process is realized to optimize the heat recovery and the integration of energy conversion units. By analogy, all water streams are listed and the potential of water recuperation is also calculated. The combination of appropriate refrigeration and heat pump cycles leads to an important energy saving potential. The respective flow rates are defined by optimization. The application case of a typical dairy process is used to calculate the energy and operating cost savings potential as well as its corresponding investment costs and payback rates.
\end{abstract}

Keywords: Energy integration; pinch analysis method; heat pumps; dairy.

\section{Introduction}

Heat pump technology has a high potential to use energy more rationally in industrial processes, and thus, to reduce $\mathrm{CO}_{2}$ emissions, especially when hot and cold utilities are used at the same time. In this article electrically driven heat pumps are considered.

The optimal integration and placement of an industrial heat pump may be evaluated by pinch analysis. The goal of pinch analysis and process integration techniques is first to identify, in a system, the heat recovery potential between hot streams (to be cooled down) and cold streams (to be heated up) (Kemp, 2007). Process integration also concerns the integration of energy conversion technologies to supply the heating and cooling requirements of the process. Among the energy conversion technologies, heat pumps are able to transfer heat from a heat source to a heat sink, saving therefore both, heating and cooling requirements. An appropriate integration of heat pumps aims at identifying the optimal heat pump type, its best operating conditions and the corresponding flow rates. It is also important to consider the interactions between the heat pumping system, the process and other energy conversion technologies.

A typical dairy process is analyzed in this article. A lot of waste heat is produced and a conceivable solution to use this heat is necessary. Currently this heat is lost; projects to sell this heat have been evaluated. A systematical analysis with pinch and exergy techniques, including a combined water-energy approach, will be detailed in this article. The minimum energy requirement is evaluated and the integration of optimal utilities is analyzed. It will be shown that heat pumps have a high potential to valorize waste heat in the process.

\section{Heat pump integration based on pinch anal- ysis with exergy factors}

The optimal integration, and positioning, of an industrial heat pump is evaluated by pinch analysis. This is widely discussed in the literature. Lots of publication cited below about industrial heat pumps integration were written between 1980 and 1990. Nowadays, heat pumps become interesting again because of higher fuel costs, but saving potential is only fully exploited when the heat pump is correctly integrated in the process. Rules for optimal placement of a heat pump in an industry process have been introduced by Linnhoff and Townsend (1983). The major contribution of the proposed approach is to adopt a system vision, considering heat pump integration with a global perspective, instead of searching for local benefit at the implementation level. Loken (1985) has analyzed the integration of heat pump in a process using a computer program that systematically allows one 
to change the temperature level of individual streams, involved in the heat pump. The approach takes into account the pinch location. However there is no systematic approach to calculate the optimal operating conditions of the heat pump in the system.

The integration of heat pumps in industry requires the complete understanding of thermodynamics, process economy, and the utility system integration. For example, Ranade (1987) presents a general equation which defines the best economic temperature lift, corresponding to the difference between the two temperature levels, for a heat pump system. As demonstrated by Wallin and Berntsson (1994), characteristics of both, industrial process and heat pumps, must be taken into account. The analysis of the process composite curves helps to identify proper heat pump types and temperature levels. The same authors (Wallin and Berntsson, 1990) propose a methodology to optimize heat source and heat sink temperatures, heat pumps size and the choice of streams used by the heat pump. In his thesis, Leyland (2002), has developed a multi objective optimization approach to define the optimal placement of temperature levels in a heat cascade. An algorithmic approach has also been developed by Dubuis (2007).

Different optimization strategies can be found in the literature: Colmenares and Seider (1987) present a non linear optimization method to place heat pumps across the pinch point. Swaney (1989) proposes a transportation model to determine the optimal heat load of heat pumps by using fixed temperature levels. Shelton and Grossmann (1986) propose a mixed linear integer programming model to show the economic potential of properly integrated heat recovery networks and refrigeration systems. Maréchal et al. (2002) have developed a tool to optimize the integration of refrigeration systems. This approach optimizes the flow rates in refrigeration systems. As demonstrated in (Maréchal, 1997), the mixed integer linear programming (MILP) formulation of the heat cascade can be used to optimize the flow rates in heat pumping systems. The interest of applying these optimization methods is to consider simultaneously the heat cascade, electricity consumption and production balances. This allows one to evaluate, in the same problem, the combined use of different utilities like cogeneration and heat pumping systems.

More recently, Holiastos and Manousiouthakis present a mathematical formulation for the optimal integration of heat pumps. The formulation evaluates the minimum hot/cold/electric utility cost and introduces a linear dependence on the number of temperature intervals (Holiastos and Manousiouthakis, 2002). Bagajewicz and Barbaro (2003) consider temperature levels as decision variables to avoid discrete temperature levels which need a fine interval partition to find good solutions. This can give non realistic solutions, due to the fact that generally, industrial heat pumps only have one condenser and one evaporator. They also make a difference between assisting heat pumps (situated above or be- low the pinch) and effective heat pumps (situated across the pinch point). Economically, an assisting heat pump in combination with an effective heat pump can be optimal. Also Holiastos and Manousiouthakis (2002) find an optimal case where the heat pump does not cross the pinch point. Berntsson mentions that heat pumps below or above the pinch can be economically interesting, for example when heat exchange gets expensive due to large distances between streams (Berntsson, 2002). One could argue in this case, that this corresponds to an inappropriate choice of the $\Delta T_{\min }$ value.

Périn-Levasseur et al. (2008) have analyzed the integration of heat pumps in a multi-effect evaporators system. They propose a three level heat pumping system, in which the optimal flows are evaluated. The system analysis concludes that only a part of the heat load available has to be pumped and that heat pumping will deliver their energy savings only if they are installed simultaneously. However their study is concentrated on a multi-effect evaporator and they do not consider the whole system.

Exergy factors help to identify the optimal integration of utilities. Wall and Gong (1995) consider an exergy concept in addition to pinch technology for optimizing heat pump integration. Staine and Favrat (1996) include exergy factors to process integration. For this they propose a graphical representation method to show the main exergy losses, which is particularly useful when introducing heat pumps or cogeneration units. Maréchal and Favrat (2006) discuss the application of exergy concepts to design the optimal energy conversion systems for given processes.

In this paper, we will show that the rule for optimal placement is still valid but has to be adapted, considering the multiple utility pinch points created by optimal integration of heat pumps and the utility system. It is also shown that the optimal combination of appropriate utilities is crucial in process integration.

\section{Performance indicators for heat pump inte- gration}

The coefficient of performance $(C O P)$ of a heat pump is defined in Eq. (1). $\dot{Q}_{t h}$ is the heat delivered by the heat pump and $\dot{E}_{h p}$ is the electricity consumed by the compressor.

$C O P=\frac{\dot{Q}_{t h}}{\dot{E}_{h p}}$

In the following, we will calculate the performance of a the heat pump, considering that the heat delivered by the heat pump will substitute the same amount of heat, originally supplied by a cogeneration system with a thermal efficiency $\eta_{t h}$ and an electrical efficiency $\eta_{e l}$. Its cost is expressed by Eq. (2). When a boiler is used, $\eta_{e l}=0$.

$\operatorname{Cost}_{\text {Cog }}=\dot{Q}_{t h} \cdot d\left(\frac{c_{f u e l}}{\eta_{t h}}-\frac{c_{e l} \cdot \eta_{e l}}{\eta_{t h}}\right)$ 
In function of the annualized investment cost and maintenance cost, the profitability condition of integrating a heat pump is defined by Eq. (3).

$$
\begin{array}{r}
I \cdot\left(\frac{i(i+1)^{n}}{(1+i)^{n}-1}\right)+M \\
+\dot{Q}_{t h} \cdot d\left(\frac{c_{e l}}{C O P}-\frac{c_{f u e l}}{\eta_{t h}}+\frac{c_{e l} \cdot \eta_{e l}}{\eta_{t h}}\right) \leq 0
\end{array}
$$

The factor $k_{\text {cost }}$ is introduced as the ratio of electricity and fuel price and Eq. (3) is transformed in Eq. (4).

$$
\begin{array}{r}
I \cdot\left(\frac{i(i+1)^{n}}{(1+i)^{n}-1}\right)+M \\
+\frac{\dot{Q}_{t h} \cdot d \cdot c_{f u e l}}{\eta_{t h}}\left(k_{\text {cost }}\left(\frac{\eta_{t h}}{C O P}+\eta_{e l}\right)-1\right) \leq 0
\end{array}
$$

The profitability of the heat pump is therefore defined by Eq. (5). It depends on the investment cost and the way it is annualized (depending on expected life time and interest rate), the maintenance cost, the fuel to electricity price ratio, the COP of the system and the efficiencies $\left(\eta_{t h}, \eta_{e l}\right)$ of the present heating system (e.g. cogeneration engine or boiler).

$$
\frac{I \cdot\left(\frac{i(i+1)^{n}}{(1+i)^{n}-1}\right)+M}{\left(1-k_{\text {cost }}\left(\frac{\eta_{t h}}{C O P}+\eta_{e l}\right)\right)} \leq \frac{\dot{Q}_{t h} \cdot d \cdot c_{f u e l}}{\eta_{t h}}
$$

$\frac{\dot{Q}_{t h} \cdot d \cdot c_{f u e l}}{\eta_{t h}}$ corresponds to the present fuel costs of the system.

From Eq. (4) the operating cost savings can be deduced.

$$
\Delta \text { Cost }_{o p}=\left(\frac{c_{f u e l}}{\eta_{t h}}-\frac{c_{e l} \cdot \eta_{e l}}{\eta_{t h}}-\frac{c_{e l}}{C O P}\right) \dot{Q}_{t h} \cdot d
$$

Eq. (7) gives the relative operating cost saving potential as a function of $k_{\text {cost }}$.

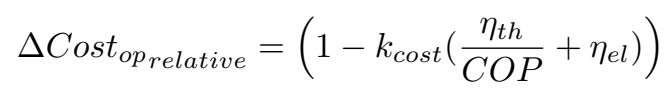

Considering the specific $\mathrm{CO}_{2}$ emissions of both, electricity and fuel, the heat pump integration may result in considerable primary energy and $\mathrm{CO}_{2}$ emissions savings. According to the IEA (International Energy Agency) Heat Pump Center, heat pumps could save up to $5 \%$ of the total $\mathrm{CO}_{2}$ emissions in industry (IEA-CO2, 2008). In addition to the profitability factors, $\mathrm{CO}_{2}$ savings also depend on:

- $\mathrm{CO}_{2}$ content of the fuel $\left(\mathrm{CO}_{2 \text { fuel in }}\right.$ $k g_{C O 2} / k W h_{L H V}$ ); (in this paper natural gas is used as fuel)

- $\mathrm{CO}_{2}$ content of the driving energy (electricity in this paper), the $\mathrm{CO}_{2}$ content $\left(\mathrm{CO}_{2 e l}\right.$ in $\left.k g_{C O 2} / k W h_{e l}\right)$ depends strongly on the electricity mix.
By using heat supplied from a heat pump, the $\mathrm{CO}_{2}$ saving is expressed by Eq. (8).

$\Delta C O_{2}=\left(\frac{C O_{2 f u e l}}{\eta_{t h}}-\frac{C O_{2 e l} \cdot \eta_{e l}}{\eta_{t h}}-\frac{C O_{2 e l}}{C O P}\right) \dot{Q}_{t h} \cdot d$

$k_{\mathrm{CO}_{2}}$ is introduced as the ratio of $\mathrm{CO}_{2}$ content of electricity and fuel. The relative $\mathrm{CO}_{2}$ emissions reduction is expressed by Eq. (9).

$\Delta C O_{2 \text { relative }}=\left(1-k_{\mathrm{CO}_{2}}\left(\frac{\eta_{t h}}{C O P}+\eta_{\text {el }}\right)\right)$

The interest of heat pumps will therefore increase if the $\mathrm{CO}_{2}$ content of the electricity is small, the $\mathrm{CO}_{2}$ content of the substituted fuel is high, the COP of the heat pump is high and the efficiency of the boiler is low.

By analogy, primary energy savings can be introduced by Eqs. (10) and (11).

$$
\begin{aligned}
& \Delta E_{p r}=\left(\frac{E_{p r f u e l}}{\eta_{t h}}-\frac{E_{p r e l} \cdot \eta_{e l}}{\eta_{t h}}-\frac{E_{p r e l}}{C O P}\right) \dot{Q}_{t h} \cdot d \\
& \Delta E_{p r_{\text {relative }}}=\left(1-k_{E_{p r}}\left(\frac{\eta_{t h}}{C O P}+\eta_{e l}\right)\right)
\end{aligned}
$$

The saving potential of a heat pump can be estimated when the temperatures levels of the heat pump cycle are known. The COP of a heat pump depends on the temperature lift and the sink temperature. It can be defined as a first approximation by considering an efficiency with respect to the theoretical value $\left(\eta_{\text {cop }}\right)$. The COP of a heat pump is defined by Eq. (12) and may be estimated considering the Carnot factor. Typical value for $\eta_{c o p}$ is $55 \%$. With Eq. (12) Eq. (7) becomes Eq. (13).

$$
\begin{array}{r}
C O P=\frac{\dot{Q}_{t h}}{\dot{E}_{h p}}=\eta_{C O P} \frac{T_{\text {sink }}}{T_{\text {sink }}-T_{\text {source }}} \\
\Delta \text { Cost }_{\text {op }_{\text {relative }}}= \\
\left(1-k_{\text {cost }} \cdot \frac{\eta_{t h}}{\eta_{C O P}} \cdot \frac{T_{\text {sink }}-T_{\text {source }}}{T_{\text {sink }}}\right)
\end{array}
$$

Eqs. (9) and (11) can be transformed by analogy. According to IEA (IEA, 2009) and Eurostat (Eurostat, 2009) for energy cost and Ecoinvent (Frischknecht et al., 2005), Table 1 shows the energy prices, $\mathrm{CO}_{2}$ emissions for the electricity mix and the corresponding primary energy in different countries. The $\mathrm{CO}_{2}$ content of natural gas is considered to be $0.202 \mathrm{~kg} / \mathrm{kWh}$ and the primary energy for natural gas has a value of $4.5 \mathrm{MJ} / \mathrm{kWh}$. Table 2 defines the corresponding $\mathrm{k}$ factors.

Table 1: Cost, $\mathrm{CO}_{2}$ emission and Primary Energy for given electricity mix

\begin{tabular}{|l|l|l|l|l|}
\hline & $\begin{array}{l}c_{\text {fuel }} \\
\text { Euro } / \mathrm{kWh}\end{array}$ & $\begin{array}{l}c_{e l} \\
\text { Euro } / \mathrm{kWh}_{e l}\end{array}$ & $\begin{array}{l}C O_{2 e l} \\
\mathrm{~kg} / \mathrm{kWh}_{e l}\end{array}$ & $\begin{array}{l}E_{\text {prel }} \\
\mathrm{MJ} / \mathrm{kWh}_{e l}\end{array}$ \\
\hline $\mathrm{FR}$ & 0.0392 & 0.062 & 0.092 & 11.788 \\
\hline $\mathrm{DE}$ & 0.050 & 0.108 & 0.631 & 10.945 \\
\hline $\mathrm{CH}$ & 0.036 & 0.069 & 0.113 & 8.094 \\
\hline $\mathrm{US}$ & 0.018 & 0.052 & 0.745 & 12.399 \\
\hline
\end{tabular}


Table 2: $k$ factors

\begin{tabular}{|l|l|l|l|}
\hline & $k_{\text {cost }}$ & $k_{\mathrm{CO}_{2}}$ & $k_{E_{p r}}$ \\
\hline $\mathrm{FR}$ & 1.58 & 0.45 & 2.62 \\
\hline $\mathrm{DE}$ & 2.16 & 3.13 & 2.43 \\
\hline $\mathrm{CH}$ & 1.92 & 0.56 & 1.80 \\
\hline $\mathrm{US}$ & 2.88 & 3.69 & 2.76 \\
\hline
\end{tabular}

Figures 1 and 2 show the Cost and $\mathrm{CO}_{2}$ savings that could be achieved as a function of the heat sink temperature for different temperature lifts. The graphs are drawn in the case of replacing the heat amount of a boiler system $\left(\eta_{t h}=0.9, \eta_{e l}=0\right)$. The saving potential is compared between France (FR) and Germany (DE). $\eta_{C O P}$ is considered to be 0.55 . The ambient temperature is supposed to be $15^{\circ} \mathrm{C}$. The bold curves separate the case where the heat source is below the ambient temperature (on the left) from the case where it is above ambient temperature (on the right); $\left(\operatorname{deltaT}=\mathrm{T}_{\text {sink }}-\mathrm{T}_{\text {source }}\right)$.

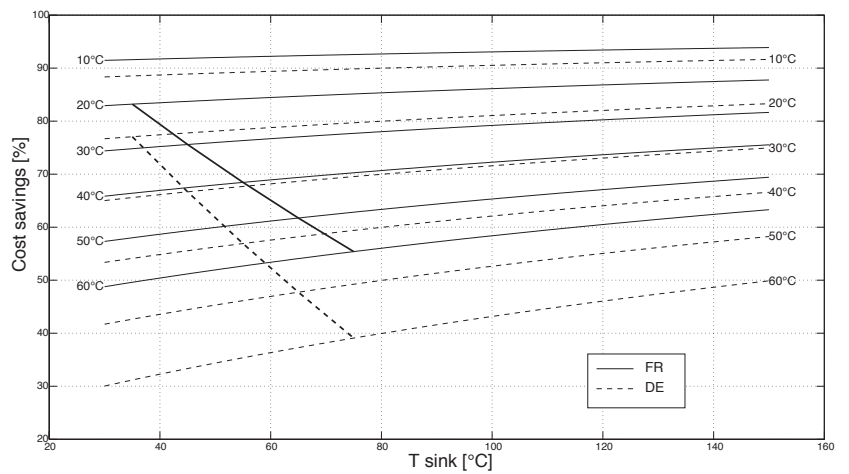

Figure 1: Relative operating costs saving (Eq. (7)/ (13)) as a function of the sink temperature and the temperature lift

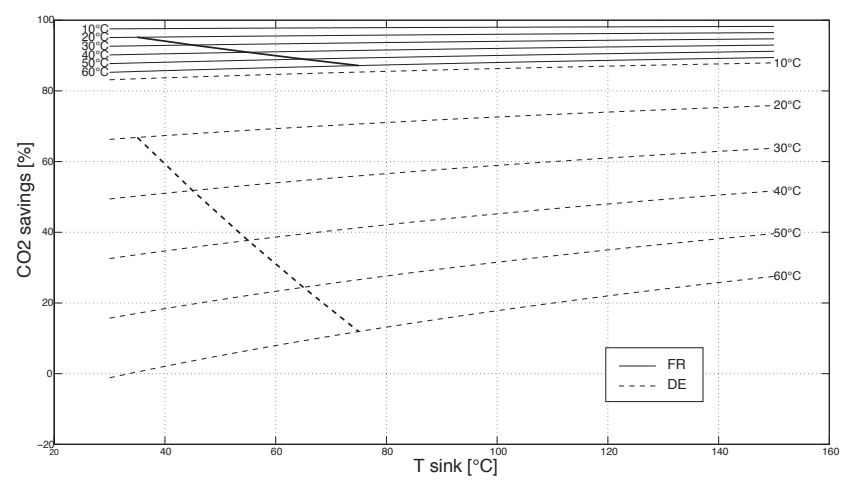

Figure 2: Relative $\mathrm{CO}_{2}$ emissions savings (Eq. (9)) as a function of the sink temperature and the temperature lift

One should note that due to the low $\mathrm{CO}_{2}$ content of the French electricity mix, the interest of heat pumps is not at the same scale as the one in Germany. Data is also available for Switzerland and US.

\section{A methodology to estimate heat pump inte- gration}

The used process analysis methodology has been described by Muller et al. (2007). It includes the systematic process unit operation analysis in order to define the hot and cold streams of the process and applies the methodology proposed by Maréchal and Kalitventzeff (1998) for energy integration in industrial sites. They use a MILP formulation to define the optimal flow rates for appropriate utilities.

These tools have been used to study heat pump integration opportunities. Figure 3 summarizes the applied methodology. Because heat pumps are often applied in processes, using water, like food or pulp and paper industry, a combined water and energy analysis should be applied. The first step consists in defining the temperature - enthalpy profile of the heat transfer requirements and the quality - flow rate profile of the water usage in the process operation units. Considering the system boundaries, a lot of renewable heat is found in the effluent streams which are systematically cooled down to the ambient temperature. This corresponds to possible new heat exchangers.

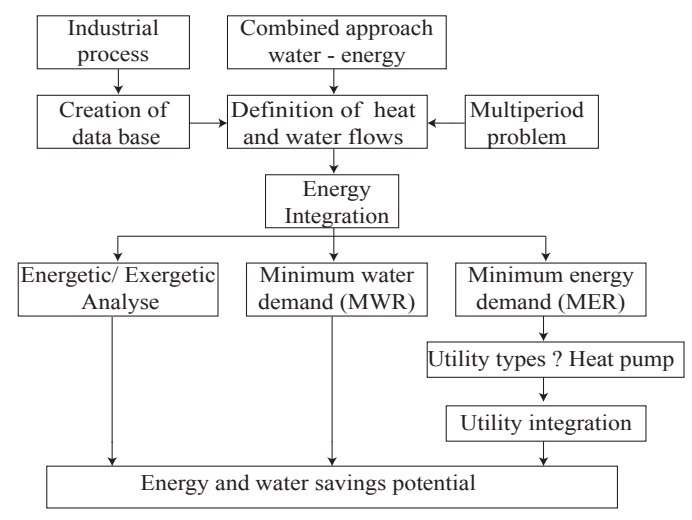

Figure 3: Heat pump integration methodology

The two main advantages of this approach are:

- Maximum heat recovery potential is calculated, since all effluents leave the process at ambient temperature.

- Water saving potential is evaluated, by performing a water producer-consumer cascade analysis at ambient temperature. The analogy between thermal energy and water is shown in Table 3 .

In order to determine the flow rates for the utility streams, the heat balance is performed in each corrected temperature interval (from higher temperature interval $\mathrm{T}_{k+1}$ to lower temperature interval $\mathrm{T}_{k}$ ) by Eq. (15). The corrected temperatures are obtained by assuming 
a minimum temperature difference (dTmin approach). The algorithm minimizes the operating cost of fuel and electricity (import or export) in Eq. (14).

Table 3: Analogy energy - water integration

\begin{tabular}{|l|l|}
\hline Thermal Energy cascade & Water cascade \\
\hline Temperature $=$ energy quality & Index = water quality \\
\hline Heat load & Water mass flow \\
\hline
\end{tabular}

For the electricity $\operatorname{cost} c_{e l}^{+}$is the purchase cost and $c_{e l}-$ is the selling price. $c_{f u e l}$ is the fuel price.

$F_{o b j}=\min \left(c_{f u e l} \dot{E}_{f u e l}+c_{e l}^{+} \dot{E}_{e l}^{+}-c_{e l}^{-} \dot{E}_{e l}^{-}\right)$

The decision variables are $\dot{E}_{f u e l}, \dot{E}_{e l}^{+}, \dot{E}_{e l}^{-}, \dot{R}_{k}, f_{u w}$.

$$
\begin{gathered}
\sum_{h_{k}=1}^{n s_{h, k}} \dot{M}_{h} q_{h, k}-\sum_{c_{k}=1}^{n s_{c, k}} \dot{M}_{c} q_{c, k} \\
+\dot{R}_{k+1}-\dot{R}_{k}=0 \quad \forall k=1 \ldots, n k \\
\text { electricity consumption: }
\end{gathered}
$$

$\sum_{u w=1}^{n u_{u w}} f_{u w} \dot{E}_{e l-u w}^{+}+\dot{E}_{e l}^{+}-\dot{E}_{e l-p}^{-} \geq 0$

electricity exportation:

$\sum_{u w=1}^{n u_{u w}} f_{u w} \dot{E}_{e l-u w}^{+}+\dot{E}_{e l}^{+}-\dot{E}_{e l}^{-}-\dot{E}_{e l-p}^{-}=0$

$\dot{m}_{h, w}$ is the nominal flow the hot stream $\mathrm{h}$ in unit uw.

$\dot{M}_{h}=f_{u w} * \dot{m}_{h, w}$

$\dot{m}_{c, w}$ is the nominal flow the cold stream c in unit uw.

$\dot{M}_{c}=f_{u w} * \dot{m}_{c, w}$

The multiplication factor is limited by a minimum and a maximum value. The associated entire variable $y_{u w}$ defines if the utility unit uw is added to process $\left(y_{u w}=1\right)$ or $\operatorname{not}\left(y_{u w}=0\right)$.

$y_{u w} * f_{u w}^{\min } \leq f_{u w} \leq y_{u w} * f_{u w}^{\max }$

The utilities are dimensioned that the process demand is satisfied. The corresponding thermodynamical feasibility is guarantied by Eqs. (21) and (22).

$\dot{E}_{e l}^{+} \geq 0 \quad \dot{E}_{e l}^{-} \geq 0$

$\dot{R}_{1}=0, \dot{R}_{n k+1}=0 \quad \dot{R}_{k}^{-} \geq 0 \quad \forall k=2 \ldots, n k$

Hot and cold streams can be process streams or utility streams. The difference is that the mass flow rate is fixed for process streams, and variable for utility streams in order to optimize the appropriate flow rates.

By analogy the mass-balance for water consumptions (co) and productions (pr) can be computed. In this case the interval corresponds to the water quality index. The algorithm minimizes the excess water flow rates after each index interval (23).

$$
\begin{array}{r}
F_{o b j}=\min \left(R W_{k+1}\right) \\
\sum_{p r_{k}=1}^{n s_{p r, k}} \dot{M}_{p r, k}-\sum_{c o_{k}=1}^{n s_{c o, k}} \dot{M}_{c o, k} \\
+R \dot{W}_{k+1}-R \dot{W}_{k}=0 \quad \forall k=1 \ldots, n_{k}
\end{array}
$$

With these equations the minimum energy and water requirements can be evaluated. To satisfy the process energy demand, appropriate utilities are chosen and corresponding optimal mass-flow rates are computed.

To simplify, only one period will be detailed in this article. However, in order to estimate the investment costs and payback rate, it is important to consider a multi-period strategy as described in (Maréchal and Kalitventzeff, 2003).

\section{Example of application}

\subsection{Process Description}

In this dairy process, milk is transformed to produce concentrated milk, pasteurized milk and cream, yoghurts and desserts. This is mainly achieved by heat exchanges and evaporation. Operating temperatures and flow rates are fixed by the process recipes. Table 4 presents the hot and cold streams of the dairy under study. The process is described in Figure 4 . The received milk in the dairy is first cooled down and stored. In the process the milk is treated by pasteurizing. The milk is first preheated and the cream is separated by centrifugation. Both milk and skimmed milk are pasteurized and then cooled down to the storage temperature conditions.

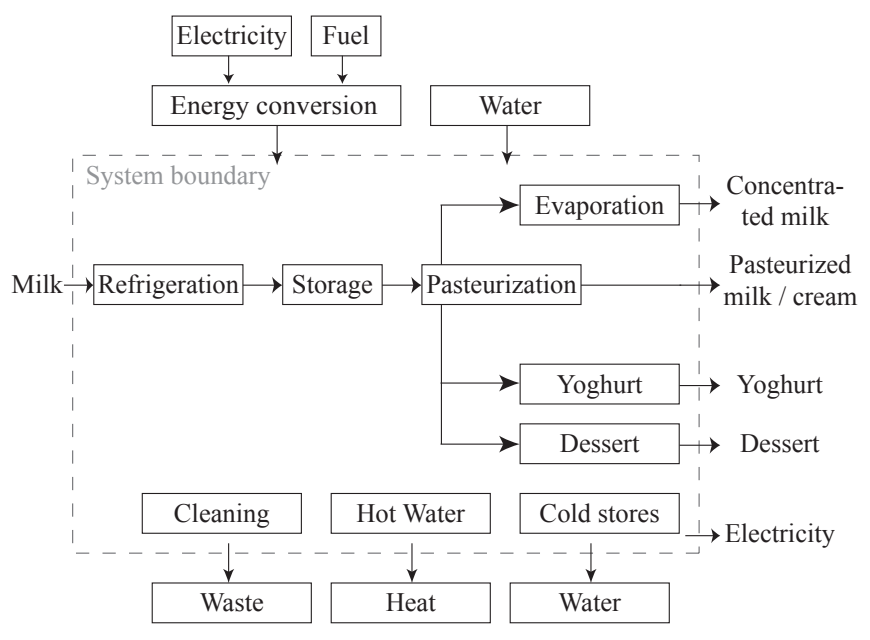

Figure 4: Process description

The pasteurized milk is distributed between concentrated milk, yoghurt and dessert lines. 
Table 4: Hot and cold streams of the process

\begin{tabular}{|c|c|c|c|c|}
\hline Unit & $\mathrm{T}_{\text {in }}\left[{ }^{\circ} \mathrm{C}\right]$ & $\mathrm{T}_{\text {out }}\left[{ }^{\circ} \mathrm{C}\right]$ & Heat Load [kW] & Remark \\
\hline Refrigeration & 6 & 4 & 76.00 & Refrigeration inlet milk \\
\hline \multirow{5}{*}{ Pasteurization } & 4 & 66 & 2356.00 & Preheating \\
\hline & 66 & 86 & 676.40 & Pasteurization milk \\
\hline & 86 & 4 & 2773.24 & Refrigeration milk \\
\hline & 66 & 98 & 119.68 & Pasteurization cream \\
\hline & 98 & 4 & 351.56 & Refrigeration cream \\
\hline \multirow{11}{*}{ Evaporation } & 4 & 70.32 & 504.03 & Preheating \\
\hline & 70.32 & 70.32 & 904.17 & Evaporation 1.effect \\
\hline & 66.42 & 66.42 & 864.11 & Evaporation 2.effect \\
\hline & 60.82 & 60.82 & 849.80 & Evaporation 3.effect \\
\hline & 60.82 & 4 & 151.48 & Refrigeration concentrated milk \\
\hline & 68.87 & 68.87 & 904.17 & Condensation 1.effect \\
\hline & 65.86 & 65.86 & 864.11 & Condensation 2.effect \\
\hline & 60.08 & 60.08 & 849.80 & Condensation 3.effect \\
\hline & 68.87 & 15 & 87.82 & Refrigeration condensates 1.effect \\
\hline & 65.86 & 15 & 80.79 & Refrigeration condensates 2.effect \\
\hline & 60.08 & 15 & 69.72 & Refrigeration condensates 3.effect \\
\hline \multirow{2}{*}{ Yoghourt } & 4 & 95 & 1026.00 & Heating \\
\hline & 95 & 10 & 957.60 & Cooling \\
\hline \multirow{2}{*}{ Dessert } & 4 & 90 & 817.00 & Heating \\
\hline & 90 & 70 & 190.00 & Cooling \\
\hline Cold stores & 5 & & 300 & Maintain the store at $5{ }^{\circ} \mathrm{C}$ \\
\hline Hot water & 15 & 55 & 167.2 & Production of hot water \\
\hline \multirow{4}{*}{ CIP } & 58.72 & 70 & 188.60 & Maintain temperature CIP 1 \\
\hline & 65 & 15 & 104.5 & Recuperation waste heat CIP 1 \\
\hline & 67.47 & 85 & 285.13 & Maintain temperature CIP 2 \\
\hline & 75 & 15 & 125.4 & Recuperation waste heat CIP 2 \\
\hline
\end{tabular}

One of the main energy consumer is the milk evaporation process. The milk is heated up and then sent to a three effects evaporator. Steam is used in the first effect to evaporate a part of the milk. The evaporated milk is then used for heating up the inlet milk stream and to evaporate the milk in the second effect. The same principle is used in the third effect. The evaporation temperature is higher than the saturation temperature and depends on the solid content of milk. To ensure the heat recovery in the evaporator, the pressure in the following effect decreases. The evaporation temperatures and pressures for each effect are given in Table 5 .

Table 5: Operating conditions of multi-effect evaporator

\begin{tabular}{|l|l|l|l|}
\hline Effect & 1 & 2 & 3 \\
\hline $\mathrm{T}_{\text {eva }}\left[{ }^{\circ} \mathrm{C}\right]$ & 70.32 & 66.42 & 60.82 \\
\hline $\mathrm{P}[$ bar $]$ & 0.31 & 0.26 & 0.20 \\
\hline
\end{tabular}

A part of the evaporated milk in the third effect is also used to preheat milk feed and the rest is cooled down with cold water. The energy requirements for the yoghurt and dessert lines is heating up the milk, and after homogenization, cooling down the product to the storage temperature.

In process integration, it is also important to consider the auxiliary processes outside the direct process lines, like the cleaning in place (CIP) system, the hot water production and the cold stores.

\subsection{Energy integration}

First the heat recovery potential between hot and cold streams is identified. For this, hot and cold streams of the process have to be defined.

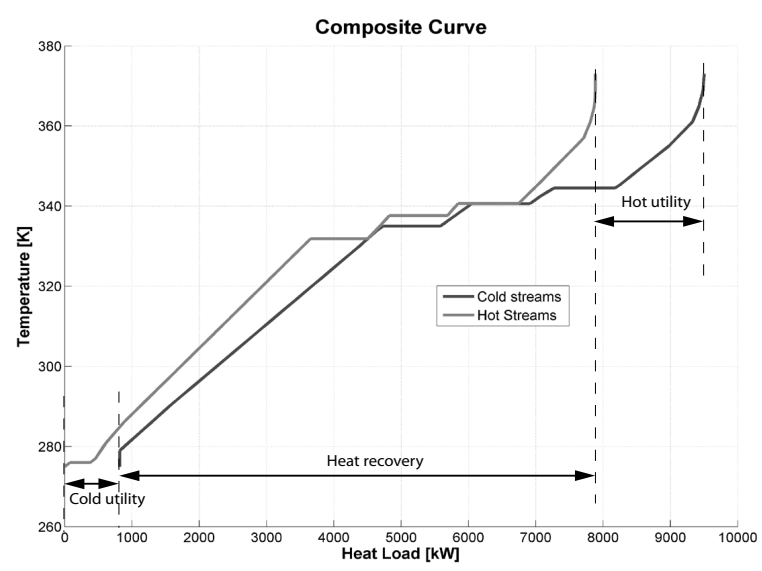

Figure 5: Hot and cold composite curves in the corrected temperature domain

Based on the definition of a minimum temperature difference $(\Delta \mathrm{Tmin})$, the minimum energy requirement (MER) is computed and the maximum energy recovery 
Table 6: Water consumption $\&$ production

\begin{tabular}{|c|c|c|c|c|c|c|c|}
\hline & \multicolumn{4}{|c|}{ Water consumptions $[\mathrm{kg} / \mathrm{s}]$} & \multicolumn{3}{|c|}{ Water productions $[\mathrm{kg} / \mathrm{s}]$} \\
\hline & $\begin{array}{l}\text { Used water } \\
\text { level } 2\end{array}$ & $\begin{array}{l}\text { Used water } \\
\text { level } 1\end{array}$ & Fresh water & Soft water & Dirty & $\begin{array}{l}\text { Used water } \\
\text { level } 2\end{array}$ & $\begin{array}{l}\text { Used water } \\
\text { level } 1\end{array}$ \\
\hline Index & 50 & 100 & 150 & 200 & 10 & 60 & 110 \\
\hline $\begin{array}{l}\text { CIP solution } \\
\text { CIP hot water } \\
\text { CIP cold water }\end{array}$ & & $\begin{array}{l}-0.5 \\
-0.55\end{array}$ & -0.475 & & 0.475 & 0.5 & 0.55 \\
\hline Milk evaporation & & & & & & 0.4 & \\
\hline Boiler & & & & -0.26 & & & \\
\hline Hot water & & & -1.5 & & 1.5 & & \\
\hline Other & -1 & & & & 1 & & \\
\hline
\end{tabular}

between process streams is calculated. The composite curve of Figure 5 shows three zones: the hot and cold utility requirements and the heat recovery.

By analogy the water pinch analysis is performed. The water production and consumption are defined in Table 6 . Figure 6 shows the minimum water requirement and its corresponding required water quality.

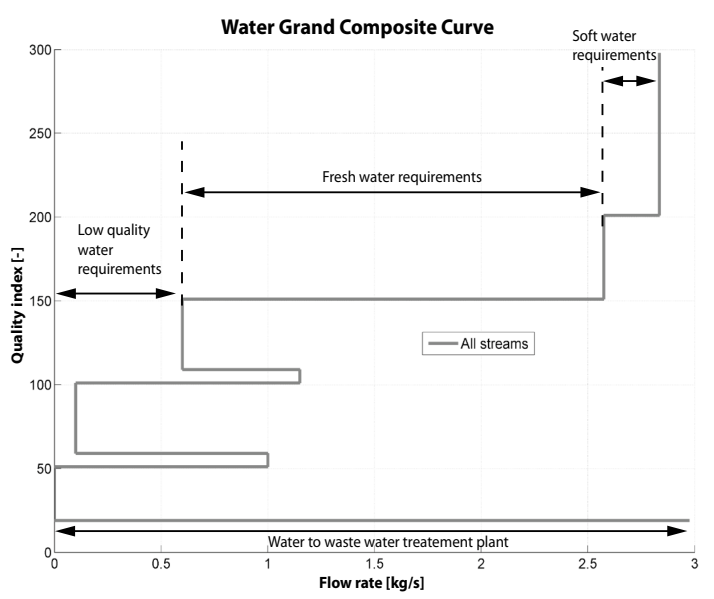

Figure 6: Water grand composite curve

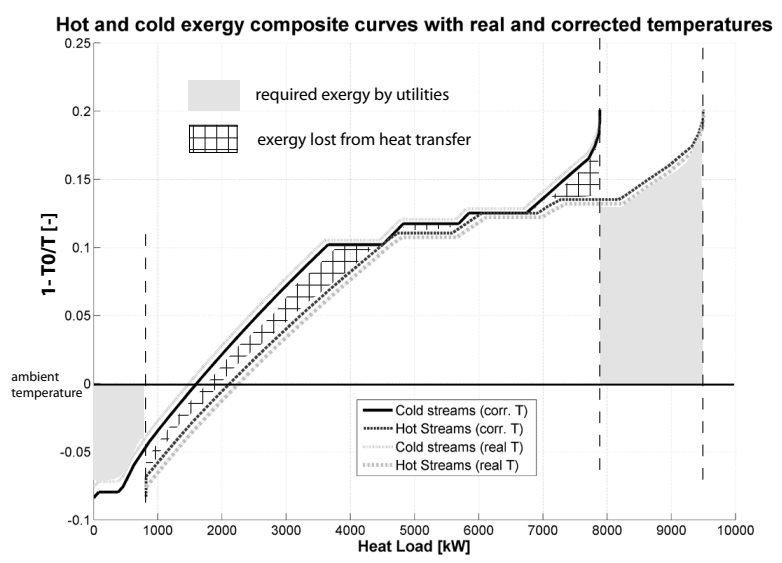

Figure 7: Carnot hot and cold composite curves
In the present situation the water consumption is $4.025 \mathrm{~kg} / \mathrm{s}$. The calculation of the water consumption corresponds therefore to a process water saving of $25 \%$. Figure 7 presents the Carnot hot and cold composite curves. Instead of representing temperatures on y-axis, Carnot factor is used $\left(\theta=1-\frac{T 0}{T}\right)$. Areas in this graph represent the required exergy to be supplied or removed, by hot and cold utilities, and the exergy losses in the heat recovery system that could be eventually valorized in the energy conversion system.

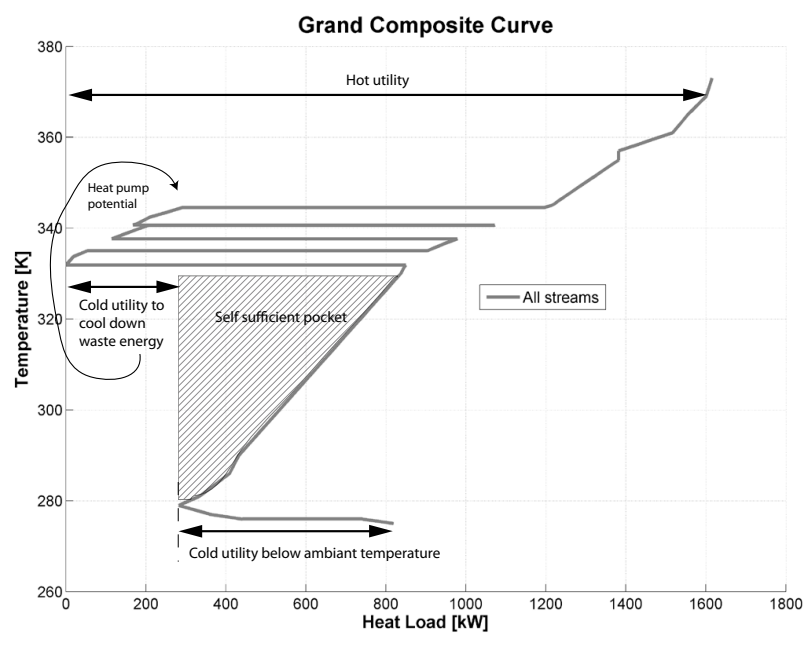

Figure 8: Process grand composite curve

In a second step, the utility system has to be first analyzed and then optimized. In the grand composite curve of Figure 8, the pinch point at a corrected temperature of $59{ }^{\circ} \mathrm{C}$ separates the process in two parts. It shows the required temperatures levels for the hot and cold utilities and it identifies the optimal placement of refrigeration cycles and heat pumps. The integration of utilities changes the shape of the composite curve, thus the optimal integration of heat pumps and other utilities can only be done simultaneously. In this application the pinch point is located around $59{ }^{\circ} \mathrm{C}$. Considering the pinch analysis rule, a heat pump can be integrated to bring heat from $52{ }^{\circ} \mathrm{C}$ to $82{ }^{\circ} \mathrm{C}$. 


\subsection{Heat pump and utility integration}

Currently a refrigeration cycle (REF) and a conventional boiler are implemented to satisfy the energy needs for the process. The grand composite curve of Figure 8 shows that a refrigeration cycle is necessary for satisfying the cold utility below the ambient temperature. Figure 9 shows the integration of the boiler and the refrigeration.

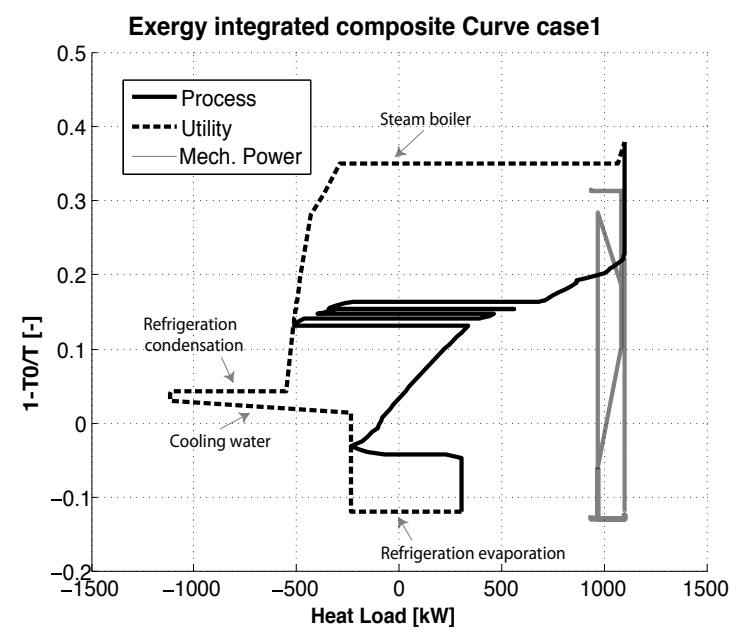

Figure 9: Integrated Carnot composite curves with refrigeration and boiler

It is shown that the heat from the condensation level of the refrigeration cannot be used in the process due to the self sufficient pocket. The heat from the condensation is considered as excess heat and has therefore be cooled down by cooling water. The waste heat from the multi-effect evaporator can be used to heat up cold process streams, but a part of the excess energy cannot not be used directly in the process and therefore has to be cooled down by a supplementary cold utility. Figure 10 shows the integration of a heat pump, refrigeration cycle and boiler.

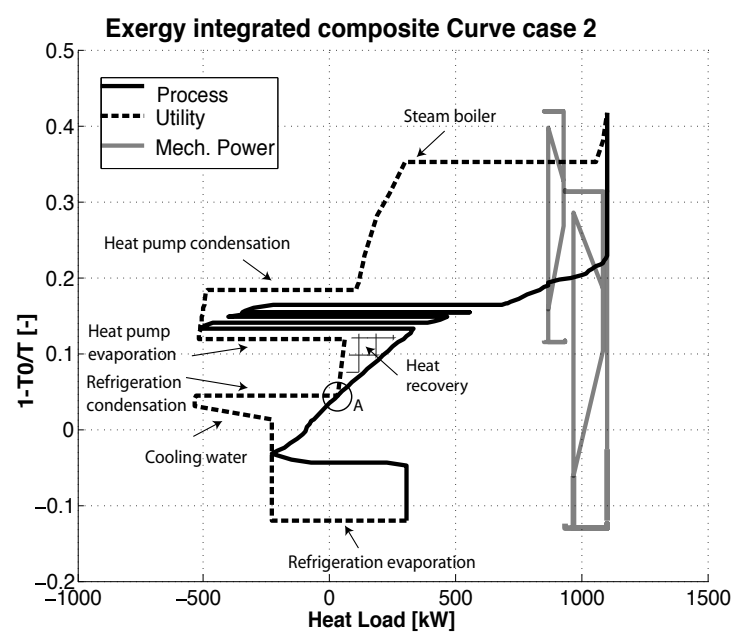

Figure 10: Integrated Carnot composite curves with refrigeration, boiler and heat pump
A heat pump (HP) offers the possibility to valorize this available heat, and to satisfy a part of the hot utility. In addition, the temperature levels are in an acceptable range for considering the integration of a cogeneration engine (COG). A cogeneration engine is fed by fuel (natural gas) and produces electricity and heat (two hot streams: the flue gases and the engine cooling) that can be used to satisfy process demand. It is important to note the dependence of utilities on each other. For example, one can see the synergy that exists between the heat pump and the refrigeration cycle: The use of the condensation heat of the refrigeration cycle to preheat process streams allows one to increase the amount of heat that could be valorized by the heat pump and therefore the heat supplied by the boiler and the cold utility supplied by cooling water are reduced. Less excess heat is available and the project to sell excess heat has to be re-evaluated.

Using the Carnot factor on the y-axis, Figures 9 - 13 show exergy integrated composite curves of the utility system. The surface between the process and the utility curve quantifies the thermal exergy losses of the heat exchange between the process and the utility system. Integrated mechanical devices (compressor for heat pump and refrigeration or cogeneration engine) are represented by the "Mech. Power" line. One can see that the use of a heat pump reduces the exergy losses of the system. Instead of using heat of the self-sufficient pocket to heat up the cold streams at rather low temperature, corresponding to certain exergy losses, a part of this heat is valorized by the heat pump to satisfy a part of the hot utility requirement. The cold streams are preheated with the condensation heat of the refrigeration cycle. The temperature differences between hot and cold streams become smaller and thus exergy losses are reduced.

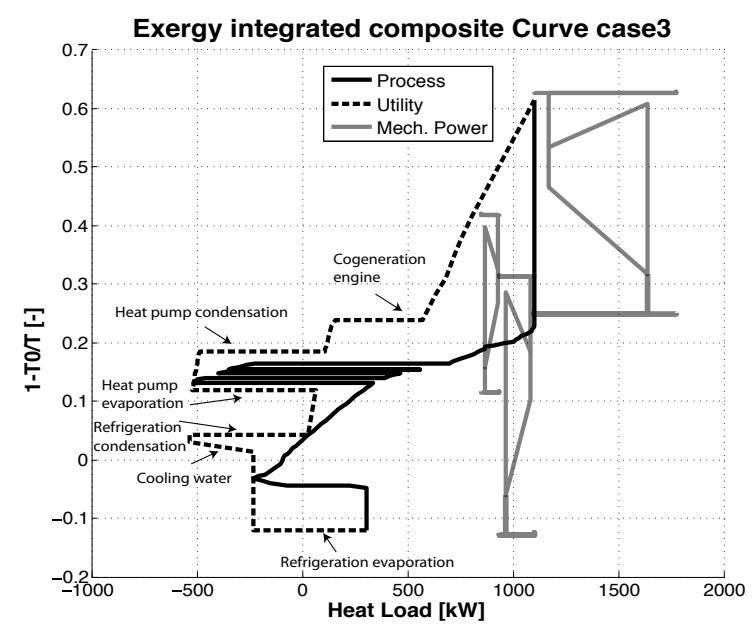

Figure 11: Integrated Carnot composite curves with refrigeration, boiler, heat pump and cogeneration engine

In Figures 11 and 13 a cogeneration engine is integrated and replaces the boiler. The produced electricity can be used to drive the heat pump, the refrigeration 
cycle and process needs and can be sold.

The stream concerned for the heat pump integration corresponds to the condensation of the last evaporation effect. This heat is used in part in the heat pump and the rest is directly recovered to preheat process streams. The optimal flow rate in the heat pumping system is obtained by optimization and activates a system utility pinch point (point A on Figure 10).

There are two ways of implementing heat pumps, either a closed cycle, shown in Figure 11, or a mechanical vapor recompression, presented in Figure 13. The principle of the mechanical vapor compression is shown in Figure 12. To optimize the mass flow rates, a new Eq. (25) is added to the MILP problem in order to create a link between the part that is recompressed and the part that is used by direct heat exchange. The mechanical vapor compression valorizes a part (around 70\%) of the vapor flow leaving the last effect of the evaporator $\left(\dot{M}_{m v r}\right)$. The rest of the waste heat is recovered by direct heat exchange $\left(\dot{M}_{d h r}\right)$.

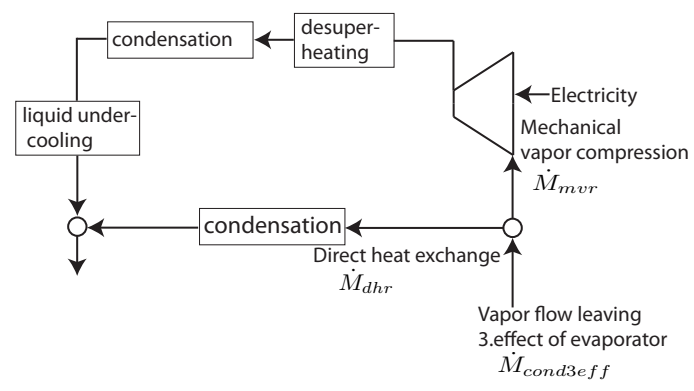

Figure 12: MVR integration

$\dot{M}_{\text {cond3eff }}=\dot{M}_{m v r}+\dot{M}_{d h r}$

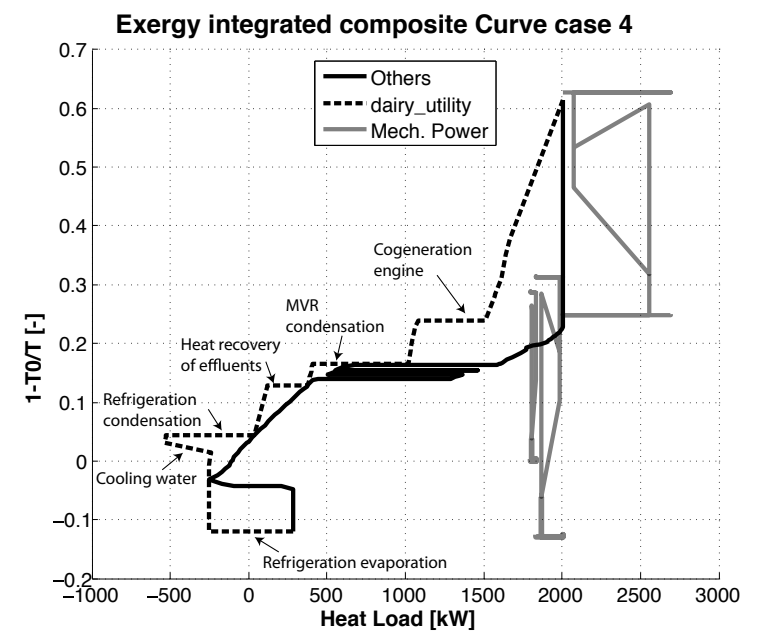

Figure 13: Integrated Carnot composite curves with refrigeration, boiler, mechanical vapour recompression and cogeneration engine
The advantage of the MVR (mechanical vapor compression) is the elimination of one heat exchanger (evaporator) which reduces both, investment cost and temperature lift on the heat pumping system.

Results and saving potentials are shown in Table 7 . Detailed results on operating costs, natural gas (NG), electricity (elec) and cooling water consumption of utilities are presented in Table 8 . The analyzed cases are compared with the current situation, where only heat recovery is considered (i.e. in pasteurization devices and the condensation heat of the first and second effect in the evaporator).

Table 8: Detailed results

\begin{tabular}{|l|l|l|l|l|l|}
\hline & {$[\mathrm{kW}]$} & $\begin{array}{l}\text { Heat re- } \\
\text { covery }\end{array}$ & HP & $\begin{array}{l}\text { HP \& } \\
\text { COG }\end{array}$ & $\begin{array}{l}\text { MVR } \\
\text { \&COG }\end{array}$ \\
\hline Process & Elec & 150 & 150 & 150 & 150 \\
Ref & Elec & 166.59 & 166.59 & 166.59 & 166.59 \\
HP & Elec & - & 83.54 & 83.54 & 35.11 \\
COG & Elec & - & - & -673.26 & -690.96 \\
\hline COG & NG & - & - & 1767 & 1814 \\
Boiler & NG & 1721 & 977 & - & - \\
\hline
\end{tabular}

\section{Discussion of heat pump integration}

The heat pump delivers $664.54 \mathrm{~kW}$ heat to the process by using $83.53 \mathrm{~kW}_{\text {el }}$ electricity. The corresponding COP of 7.9 can be calculated by Eq. (1). In the case of the MVR, $35.11 \mathrm{~kW}_{e l}$ electricity is consumed by the compressor to deliver $636.11 \mathrm{~kW}$ heat delivered to the process $(\mathrm{COP}=18.1)$.

In reality the heat pump or MVR does not satisfy only a heat demand but also a cooling demand below the pinch point, so that the definition of the COP in this case is not evident and has to be reviewed.

The characteristics of the system are: $\eta_{t h}=0.9$, $\eta_{\text {el }}=0, d=2650$ hours/year. Knowing the COP, the delivered heat, the fuel and electricity costs, and the characteristics, Eqs. (6), (8) and (10) can be solved for the heat pump cycle and the MVR. Table 9 shows the saving potential in costs, $\mathrm{CO}_{2}$ emissions and primary energy for the heat pump integration and Table 10 shows the saving potential for the MVR integration. The global $\mathrm{CO}_{2}$ savings of the whole system (including all utilities) are shown in Table 7. It is important to remark that the $\mathrm{CO}_{2}$ emission savings strongly depend on the way the grid electricity is produced.

Table 9: Heat pump integration savings per year

\begin{tabular}{|l|l|l|l|}
\hline & Cost [MEuro] & $\mathrm{CO}_{2}[$ Tons] & $\mathrm{E}_{p r}[M J]$ \\
\hline $\mathrm{FR}$ & 0.063 & 375 & 6195 \\
\hline $\mathrm{DE}$ & 0.0739 & 256 & 6382 \\
\hline $\mathrm{CH}$ & 0.0552 & 370 & 7013 \\
\hline $\mathrm{US}$ & 0.0237 & 230 & 6060 \\
\hline
\end{tabular}


Table 7: Results

\begin{tabular}{|c|c|c|c|c|c|c|}
\hline & Unit & Current & Heat recovery & HP & $\mathrm{HP} \& \mathrm{COG}$ & MVR\&COG \\
\hline Operating costs $\mathrm{CH}$ & [MEuro/year] & 0.3129 & 0.2221 & 0.1665 & 0.1298 & 0.1245 \\
\hline Saving potential & [\%] & +39 & 0 & -25 & -42 & -44 \\
\hline \multirow[t]{3}{*}{ Fuel consumption } & {$[\mathrm{kg} / \mathrm{s}]$} & 0.05 & 0.037 & 0.021 & 0.038 & 0.039 \\
\hline & {$[\mathrm{kW}]$} & 2326 & 1721 & 977 & 1767 & 1814 \\
\hline & [GJ/year] & 22186 & 16418 & 9318 & 16862 & 17305 \\
\hline Saving potential & {$[\%]$} & +40 & 0 & -43 & +3 & +5 \\
\hline \multirow[t]{2}{*}{ Electricity } & {$[\mathrm{kW}]$} & 316.77 & 316.77 & 403.07 & -265.37 & -331.81 \\
\hline & [GJ/year] & 3022 & 3022 & 3845 & -2532 & -3165 \\
\hline Saving potential & {$[\%]$} & 0 & 0 & 27 & -184 & -205 \\
\hline $\mathrm{CO}_{2}$ emissions ( $\mathrm{CH}$ mix) & [tons/year] & 1524 & 1014 & 641 & 946 & 971 \\
\hline Saving potential & {$[\%]$} & +50 & 0 & -37 & -7 & -4 \\
\hline $\mathrm{CO}_{2}$ emissions (FR mix) & [tons/year] & 1509 & 1000 & 622 & 946 & 971 \\
\hline Saving potential & {$[\%]$} & +51 & 0 & -38 & -5 & -3 \\
\hline $\mathrm{CO}_{2}$ emissions (DE mix) & [tons/year] & 1959 & 1450 & 1192 & 946 & 971 \\
\hline Saving potential & [\%] & +35 & 0 & -18 & -35 & -33 \\
\hline $\mathrm{CO}_{2}$ emissions (US mix) & [tons/year] & 2056 & 1547 & 1315 & 946 & 971 \\
\hline Saving potential & [\%] & +33 & 0 & -15 & -39 & -37 \\
\hline Cooling water consumption & {$[\mathrm{kg} / \mathrm{s}]$} & n.a. & 42.11 & 14.39 & 14.39 & 14.39 \\
\hline & [tons/year] & & 401729 & 137281 & 137281 & 137281 \\
\hline Saving potential & [\%] & & 0 & -66 & -66 & -66 \\
\hline Exergy efficiency & [\%] & n.a. & 31.1 & 43.7 & 45.9 & 47.5 \\
\hline
\end{tabular}

Table 10: MVR integration savings per year

\begin{tabular}{|l|l|l|l|}
\hline & Cost [MEuro] & $\mathrm{CO}_{2}[$ Tons] & $\mathrm{E}_{p r}[\mathrm{MJ}]$ \\
\hline $\mathrm{FR}$ & 0.0677 & 370 & 7332 \\
\hline $\mathrm{DE}$ & 0.0836 & 320 & 7410 \\
\hline $\mathrm{CH}$ & 0.061 & 368 & 7675 \\
\hline $\mathrm{US}$ & 0.0289 & 309 & 7275 \\
\hline
\end{tabular}

The profitability of a heat pump is analyzed by comparing the "heat recovery" case (reference case) with the "HP" case and the "MVR" case. Eq. (5) gives the relation. Resolving this equation, the profitability indicator is evaluated. The investment costs are evaluated by following approximation: Eq. (26). The maintenance cost is supposed to be $10 \%$ of the annualized investment costs.

$I=1.5 \cdot 1500 \cdot 160^{0.1} \cdot \dot{E}_{h p}^{0.9}$

The annualized investment cost is calculated for an interest rate of $6 \%$ and a life time of 20 years for the heat pump installation.

Table 11: Heat pump profitability

\begin{tabular}{|l|l|l|}
\hline & $\begin{array}{l}\text { HP payback time } \\
\text { [years] }\end{array}$ & $\begin{array}{l}\text { MVR payback } \\
\text { time [years] }\end{array}$ \\
\hline FR & 3.2 & 1.4 \\
\hline DE & 2.7 & 1.1 \\
\hline CH & 3.6 & 1.5 \\
\hline US & 8.5 & 3.2 \\
\hline
\end{tabular}

The investment costs are $201 \mathrm{kEuro}$ for the heat pump and $92 \mathrm{kEuro}$ for the mechanical vapor compression, which corresponds to a yearly charge (investment and maintenance) of $19.2 \mathrm{kEuro} /$ year for the heat pump and $8.8 \mathrm{kEuro} /$ year for the MVR. Table 11 shows the payback time in the context of different country locations.

\section{Sensitivity analysis}

In the presented example, the refrigeration cycle with fixed evaporation and condensation temperatures is considered. The composite curves (e.g. Figure 13) show exergy losses corresponding to the temperature difference between the evaporation of the refrigeration cycle and the process streams. The condensation temperature can be optimized, in order to maximize heat recovery by preheating. In case 4 (MVR \&COG) the operating conditions of the refrigeration cycle (e.g. temperature levels) have not been optimized. Table 12 compares the results from Case 4 with an optimized refrigeration cycle.

Table 12: Comparison of Case 4 with an optimized refrigeration cycle

\begin{tabular}{|l|l|l|l|}
\hline & Unit & $\begin{array}{l}\text { COG\& } \\
\text { MVR }\end{array}$ & $\begin{array}{l}\text { Optimized re- } \\
\text { frigeration cycle }\end{array}$ \\
\hline OC & {$[$ MEuro/year] } & 0.1245 & 0.1035 \\
\hline Process & Elec $[\mathrm{kW}]$ & 150 & 150 \\
Ref & Elec $[\mathrm{kW}]$ & 166.59 & 194.78 \\
MVR & Elec $[\mathrm{kW}]$ & 35.11 & 48.10 \\
COG & Elec $[\mathrm{kW}]$ & -690.96 & -449.43 \\
\hline COG & NG $[\mathrm{kW}]$ & 1814.0 & 1162.8 \\
\hline Cooling & Water $[\mathrm{kW}]$ & 302.32 & 39.23 \\
\hline
\end{tabular}

The evaporation temperature has been raised to reach the $\Delta T_{\min }$ constraint. A sensitivity analysis has 
been performed to find the optimal condensation temperature between. The optimal temperature of $55^{\circ} \mathrm{C}$ (maximum temperature admitted) corresponds to more heat available for the process. The consequence is that more heat can be pumped by the mechanical vapor compression (96\% from the mass flow leaving the third effect of the evaporator). This means also that the cogeneration engine becomes smaller and the cooling water consumption is reduced to less than $40 \mathrm{~kW}$. Figure 14 shows the corresponding integrated composite curves.

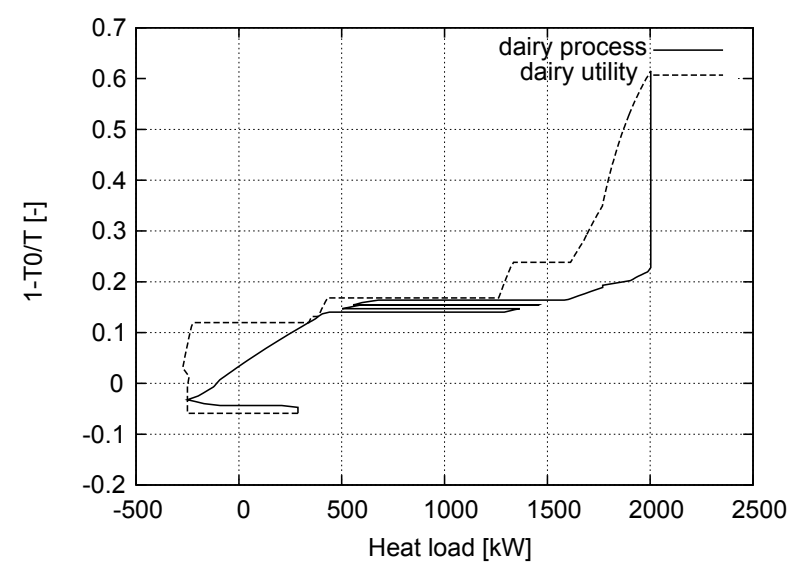

Figure 14: Integrated composite curves for optimized refrigeration cycle

Changes in the refrigeration cycle introduces different optimal mass flow rates for the mechanical vapor compression, the cogeneration engine as well as for the cooling water. The interdependence of utility is very important and has to be considered for optimizing energy systems. The next modification would be to install a multistage refrigeration system in order to optimize the process preheating.

\section{Conclusions}

A method for calculating the optimal integration of heat pumps in industrial processes has been presented. The method is part of a methodology for analyzing the energy efficiency of industrial processes and is demonstrated by an application in the food industry. Heat and water are the major utilities and production supports in the food industry, and therefore the method also integrates an analysis of the water management in the plant. Considering that both the temperature of water and its purity have a value, a combined heat and water approach is proposed. The proposed method is based on the application of process integration techniques that considers not only the heat recovery between process streams but also the integration of the energy conversion system. This is realized by applying a linear programming model that allows one calculating the optimal flows in the integrated utility system. The major advantage of the proposed approach is that it allows to consider the energy conversion system as a whole. The application of such methods shows that the model is able to represent interactions between utility streams. In the calculated solution, the heat pump not only valorizes excess heat from the process but also indirectly valorizes the heat excess of the refrigeration cycle. It is also shown that the integration of a cogeneration unit will profit from the integration of the heat pump. While providing the mechanical power to the heat pump, the cogeneration unit will supply heat to the process, that is not supplied by the heat pump. As for the primary energy savings, this value strongly depends on the electricity production mix. Applying the "more in-more out" principle, this leads also to a reduction of cooling water used in the plant.

Heat pumps savings in operating costs, $\mathrm{CO}_{2}$ emissions and primary energy are shown in the context of different countries. The thermodynamic analysis also defines an indicator of profitability of the heat pumping system by defining the break even cost of the energy conversion system investment. The investment of a heat pump is calculated by an approximate formula in order to evaluate payback times.

\section{Acknowledgements}

The authors wish to thank ECLEER (European Centre and Laboratories for Energy Efficiency Research) for supporting this research and collaborating in its realization.

\section{Nomenclature Latin letters}

$\dot{M} \quad$ Mass flow $[\mathrm{kg} / \mathrm{s}]$

$\dot{m} \quad$ Nominal mass flow $[\mathrm{kg} / \mathrm{s}]$

$\dot{E}_{e l-p}$ Consumed electricity by the process $[\mathrm{kW}]$

$\dot{E}_{e l-u w}$ Produced electricity by unit uw $[\mathrm{kW}]$

$\dot{E}_{e l} \quad$ Electricity demand or excess $[\mathrm{kW}]$

$\dot{E}_{f u e l}$ Energy delivered by fuel (natural gas) [kW]

$\dot{E}_{h p} \quad$ Electricity supply to heat pump [kW]

$\dot{Q}_{t h} \quad$ Useful heat load supplied by heat pump [kW]

$c_{e l} \quad$ Electricity price [Euro $\left./ \mathrm{kWh}_{e l}\right]$

$c_{\text {fuel }}$ Fuel price [Euro/kWh]

$\left.\begin{array}{lll}C_{2 e l} & \mathrm{CO}_{2} & \text { content of electricity }[\mathrm{kg} / \mathrm{kWh} \\ e l\end{array}\right]$

$\mathrm{CO}_{2 \text { fuel }} \mathrm{CO}_{2}$ content of fuel $[\mathrm{kg} / \mathrm{kWh}]$

COP Coefficient of performance

$d \quad$ Operating time $[\mathrm{h} /$ year]

$E_{\text {prel }}$ Equivalent primary energy of electricity $\left[\mathrm{MJ} / \mathrm{kWh}_{e l}\right]$

$E_{\text {prfuel }}$ Equivalent primary energy of fuel [MJ/kWh]

$f_{u w} \quad$ Multiplication factor of unit uw [-] 
Specific enthalpy $[\mathrm{J} / \mathrm{kg}]$

Investment cost [Euro/year]

Interest rate for the investment [-]

$k_{\mathrm{CO}_{2}}$ Electricity to fuel $\mathrm{CO}_{2}$ content ratio [-]

$k_{\text {cost }} \quad$ Electricity to fuel price ratio [-]

$k_{E_{p r}} \quad$ Electricity to fuel primary energy ratio [-]

$M \quad$ Annual maintenance cost [Euro/year]

$n \quad$ Expected life time of installation [years]

$n k \quad$ Number of temperature intervals [-]

ns Number of streams [-]

nu Number of units [-]

$q \quad$ Heat load per mass flow $[\mathrm{kJ} / \mathrm{kg}]$

$R_{k} \quad$ Cascaded heat from temperature interval $\mathrm{k}$ to the lower temperature intervals $[\mathrm{kW}]$

$R W_{k} \quad$ Cascaded water from quality interval $\mathrm{k}$ to the lower quality intervals $[\mathrm{kg} / \mathrm{s}]$

$s \quad$ Specific entropy $[\mathrm{J} /(\mathrm{kg} \mathrm{K})]$

T Temperature $[\mathrm{K}]$

T0 Ambient temperature $[\mathrm{K}]$

$T_{\text {sink }} \quad$ Hot source temperature [K]

$T_{\text {source }}$ Cold source temperature $[\mathrm{K}]$

$y_{u w} \quad$ Entire variable [-]

\section{Greek letters}

$\eta_{C O P}$ Heat pump efficiency with theoretical COP [-]

$\eta_{e l} \quad$ Electric efficiency of the cogeneration unit [-]

$\eta_{t h} \quad$ Thermal efficiency of the cogeneration unit [-]

$\Theta \quad$ Carnot Factor [-]

\section{Indices}

$\begin{array}{ll}c & \text { Cold streams } \\ c o & \text { Consumed water in the process } \\ h & \text { Hot streams } \\ k & \text { Temperature interval } \\ p r & \text { Produced water from the process }\end{array}$

\section{Superscripts}

$\max$ maximum value

min minimum value

\section{References}

Bagajewicz, M. and Barbaro, A., 2003. On the use of heat pumps in total site heat integration. Computers and Chemical Engineering Vol.27, 1707-1719.

Berntsson, T., 2002. Heat sources - technology, economy and environment. International Journal of Refrigeration Vol.25, 428-438.

Colmenares, T. and Seider, W., 1987. Heat and power integration of chemical processes. American institute of chemical engineering journal Vol.33, 898-915.

Dubuis, M., 2007. Etude thermo-économique de l'intégration des pompes à chaleur industrielles. Master's thesis, LENI - Ecole Polytechnique Fédérale de Lausanne.

Eurostat, 2009. Energy, transport and environment indicators. eurostat.

Frischknecht, R., Jungbluth, N., Althaus, H.-J., Doka, G., Dones, R., Heck, T., Hellweg, S., Hischier, R., Nemecek, T., Rebitzer, G. and Spielmann, M., 2005. The ecoinvent database: Overview and methodological framework. International Journal of Life Cycle Assessment Vol.10, 3-9.

Holiastos, K. and Manousiouthakis, V., 2002. Minimum hot/cold/electric utility cost for heat exchange networks. Computers and Chemical Engineering Vol.26, $3-16$.

IEA, 2009. Key world energy statistics. International energy agency - IEA.

IEA-CO2, 2008. Heat pumps can cut global co2 emissions by nearly $8 \%$. International energy agency - IEA.

Kemp, F., 2007. Pinch analysis and process integration: a user guide on process integration for the efficient use of energy. Second Edition, Elevier, ButterworthHeinemann,UK.

Leyland, G., 2002. Multi-objective optimization applied to industrial energy problems. Thesis, Ecole Polytechnique Fédérale de Lausanne.

Linnhoff, B. and Townsend, D., 1983. Heat and power networks in process design. part 1: Criteria for placement of heat engines and heat pumps in process networks. AIChE Journal Vol.29 No.5, 742-748.

Loken, P., 1985. Process integration of heat pumps. Heat Recovery Systems Vol.5 No.1, 39-49.

Maréchal, F., 1997. Méthode d'analyse et de syntèse énergétique des procédés industriels. Thesis, Université de Liège.

Maréchal, F., Closon, H., Kalitventzeff, B. and Pierucci, S., 2002. A tool for optimal synthesis of industrial refrigeration systems: Application to an olefins plant. New Orleans, USA. 
Maréchal, F. and Favrat, D., 2006. Combined exergy and pinch analysis for optimal energy conversion technologies integration. ECOS 2005: 18th International Conference on Efficiency, Cost, Optimization, Simulation and Environmental Impact of Energy Systems Vol.1, $177-184$.

Maréchal, F. and Kalitventzeff, B., 1998. Energy integration of industrial sites: tools, methodology and application. Applied Thermal Engineering Vol.18, 921-933.

Maréchal, F. and Kalitventzeff, B., 2003. Targeting the integration of multi-period utility systems for site scale process integration. Applied Thermal Engineering Vol.23, 1763-1784.

Muller, D., Maréchal, F., Wolewinski, T. and Roux, P., 2007. An energy management method for the food industry. Applied Thermal Engineering Vol.27, 26772686.

Périn-Levasseur, Z., Palese, V. and Maréchal, F., 2008. Energy integration study of a multi-effect evaporator. Proceedings of the 11th Conference on Process Integration, Modelling and Optimisation for Energy Saving and Pollution Reduction.

Ranade, S., 1987. New insights on optimal integration of heat pumps in industrial sites. Heat Recovery Systems \& CHP Vol.8 No.3, 255.
Shelton, M. and Grossmann, I., 1986. Optimal synthesis of integrated refrigeration systems parts 1 and 2 . Computers and Chemical Engineering Journal Vol.10 No.5, 445-459.

Staine, F. and Favrat, D., 1996. Energy integration of industrial processes based on the pinch analysis method extended to include exergy factors. Applied Thermal Engineering Vol.16, 497-507.

Swaney, R., 1989. Thermal integration of processes with heat engines and heat pumps. American institute of chemical engineering journal Vol.35, 1003-1016.

Wall, G. and Gong, M., 1995. Heat engines and heat pumps in process integration. Thermodynamics and the Design, Analysis, and Improvement of Energy Systems, ASME Vol.35, 217-222.

Wallin, E. and Berntsson, T., 1994. Integration of heat pumps in industrial processes. Heat Recovery Systems \& CHP Vol.14 No.3, 287-296.

Wallin, E. Franck, P. and Berntsson, T., 1990. Heat pumps in industrial processes - an optimization methodology. Heat Recovery Systems \& CHP Vol.10 No.4, 437-446. 